Kalpa Publications in Civil Engineering
Volume 1, 2017, Pages 441-449
ICRISET2017. International Conference on Re-
search and Innovations in Science, Engineering
\&Technology. Selected papers in Civil Engineering $\quad \mathrm{Ka} \mathrm{Loo}$

\title{
Non Linear Analysis of Single Storey RC Front Wall under Blast Loading
}

\author{
Kavita Singh ${ }^{1}$, H J Solanki ${ }^{2}$, A B Belani ${ }^{3}$ \\ ${ }^{1}$ Parul University, Vadodara, India \\ ${ }^{2}$ Parul University, Vadodara, India \\ ${ }^{3} \mathrm{~L} \& \mathrm{~T}$ Chiyoda limited,Vadodara, India \\ kavita.singheparuluniversity.ac.in, hardik.solanki@paruluniversity \\ .ac.in, abelanielntchiyoda.com
}

\begin{abstract}
In modern days many civilian structures need shielding against blast effects. Past incidences of terrorist activities have increased the awareness towards the structural design to mitigate the effect of explosion and prevention of collapse of the building. The objective primary of blast resistant design is to prevent the collapse of the structural system and to maintain structural integrity through ductile and redundant behaviour. The primary aim of present work is to analyze the RC wall having SDOF with both end fixed under blast loading using ANSYS software.
\end{abstract}

Keywords-Blast load, single degree of freedom system, ANSYS software.

\section{Introduction}

If the threat of terrorist action cannot be stopped, Damage to the assets, loss of life and social panic are factors that have to be minimized. Also designing the structures as fully blast resistant is not a realistic and also not economical, however current engineering knowledge can enhance the new and existing buildings to reduce the effects of an explosion. The term blast is commonly used to describe any situation in which rapid release of energy occurs from a chemical, mechanical or nuclear source. However, from the point of view of the effects of explosions upon structural systems, there exists a set of fundamental characteristics which must be defined and considered, irrespective of the source. Conventionally buildings are constructed very differently than military structures and as such are generally very vulnerable to blast and ballistic threats. In order to design structures which are able to withstand explosions it is necessary to quantify the effects of such explosions. 


\section{Evaluation of Transformation Factor}

\subsection{Biggs shape function}

Biggs shape functions are the functions which are used to find the load factor, mass factor and load - mass factor.

Consider a simply supported beam having a uniformly distributed load(udl).

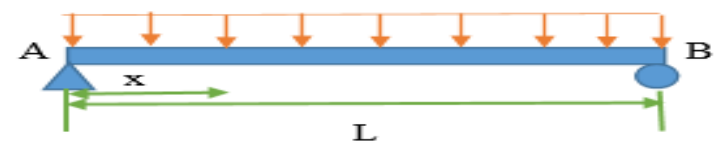

$M=\frac{W x}{2}(L-x)$

$$
\frac{d^{2} y}{d x^{2}}=\frac{M(x)}{E I}
$$

Deflection at each point

$y=\frac{W}{24 E I}\left(\frac{L^{4}}{16}-\frac{L^{4}}{4}+\frac{L^{4}}{2}\right)$

Maximum deflection

$y \max =\frac{5}{384}\left(\frac{w l^{4}}{E I}\right)$

Shape function

$\emptyset=\frac{y}{y \max }=\frac{16}{5 L^{4}}\left(L^{3} x-2 L x^{3}+x^{4}\right)$

Transformation factor

As per IS:4991-1968, the transformation factor is given as

$K L M=K M / K L$

$K M=\frac{1}{M t}\left\{\sum_{r=1}^{n} M r \emptyset r^{2}+\int m \emptyset^{2}(x) d x\right\}$

$K L=1 / P t\left\{\sum_{r=1}^{j} p r \emptyset r+\int p(x) \emptyset(x) d x\right.$

Where,

$\mathrm{Mt}=$ Total actual mass

$\mathrm{N}=$ Number of concentrated masses

$\mathrm{Mr}=$ Concentrated mass at point $\mathrm{r}$ 


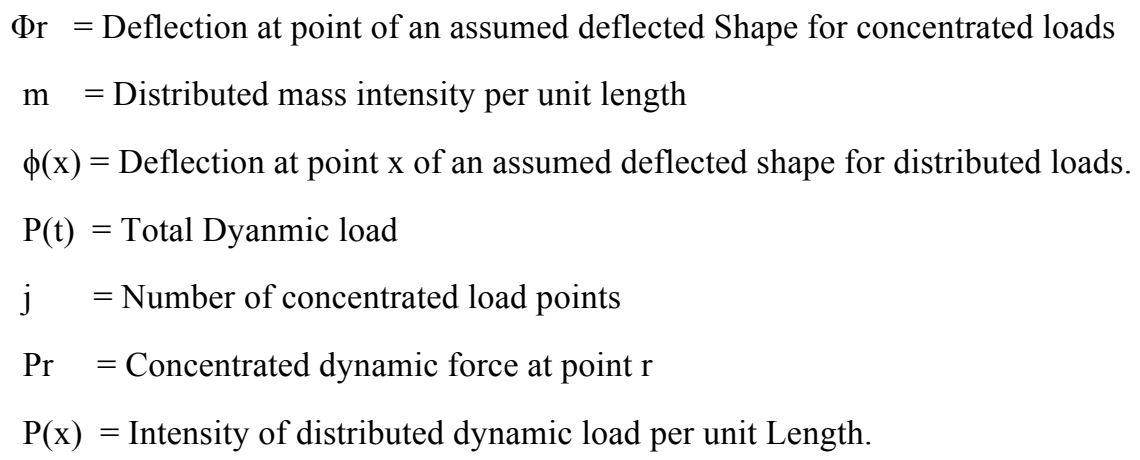

For the simply supported beam the load factor, mass factor and load mass factor are calculated as:

$$
\begin{aligned}
K L & =\frac{1}{L} \int_{0}^{L} \emptyset(x) d x \\
& =0.64 \\
K M & =\frac{1}{L} \int_{0}^{L} \emptyset^{2}(x) d x \\
& =0.50
\end{aligned}
$$

As per equation (6),

$K L M=0.78$

\section{Blast Load Calculation For the Front Wall}

The problem data is given by L\&T Chiyoda Limited which is mentioned below:

Building Height $\mathrm{H}=5.7 \mathrm{~m}$ (above ground)

Building Width $\mathrm{B}=38.4 \mathrm{~m}$

Building Length $\mathrm{L}=17.225 \mathrm{~m}$

The blast wave parameters are mentioned below:

Peak over pressure Pso: $65.0 \mathrm{kPa}$

Time duration $\mathrm{td}: 0.15 \mathrm{sec}$

Clearing distance, $\mathrm{S}$ 
$\mathrm{S}=\mathrm{H}$ or $\mathrm{B} / 2$ whichever minimum $=5.7 \mathrm{~m}$

Ambient Pressure P0 $=100.0 \mathrm{kPa}$

Shock velocity $=424.27 \mathrm{~m} / \mathrm{sec}$

Length of wave $\mathrm{Lw}=63.65 \mathrm{~m}$

Peak Dynamic Wind Pressure, $\mathrm{q} 0=13.5 \mathrm{Kpa}$

The front wall is spanning vertically from foundation to roof. The design is typical wall segment $1 \mathrm{~m}$ wide.

Peak Reflected Pressure Pr $=160.84 \mathrm{kPa}$

Clearing time tc $=0.0403 \mathrm{sec}$

Drag coefficient $\mathrm{Cd}=1$

Stagnation pressure $\mathrm{Ps}=78.52 \mathrm{kPa}$

Front wall Impulse $1 \mathrm{w}=7.55 \mathrm{kPa}-\mathrm{sec}$

Effective duration te $=0.094 \mathrm{sec}$

\section{MODELLING}

A Single storey RC front wall model is shown below having following material properties:

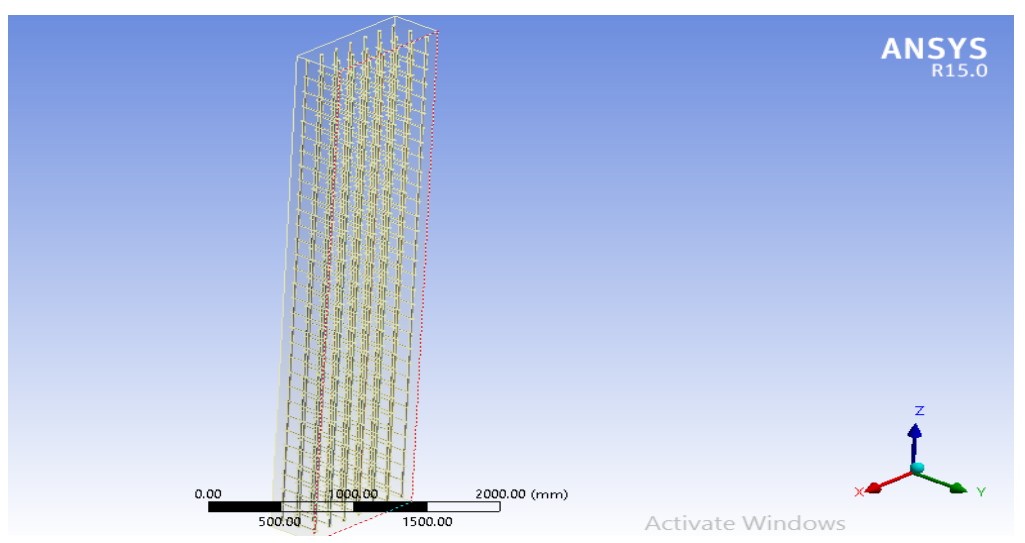

Figure 2: Model of RC wall 
Material Properties:

Elasticity of steel Es $=205000 \mathrm{~N} / \mathrm{mm} 2$

Elasticity of concrete $\mathrm{Ec}=25635 \mathrm{~N} / \mathrm{mm} 2$

Poisson's ratio $=0.3$

Main steel Dia $=20 \mathrm{~mm}$

Spacing $=150 \mathrm{~mm}$

Boundary condition: Both ends are fixed.

\section{ANALYSIS AND RESULT}

Here non- linear analysis is done and time stepping method is used for calculating force at each time period having interval of $0.002 \mathrm{sec}$ and that blast force is applied on the RC front wall.

Displacement in $\mathrm{X}, \mathrm{Y}$ and $\mathrm{Z}$ direction are obtained from the ANSYS Software and the results are shown below

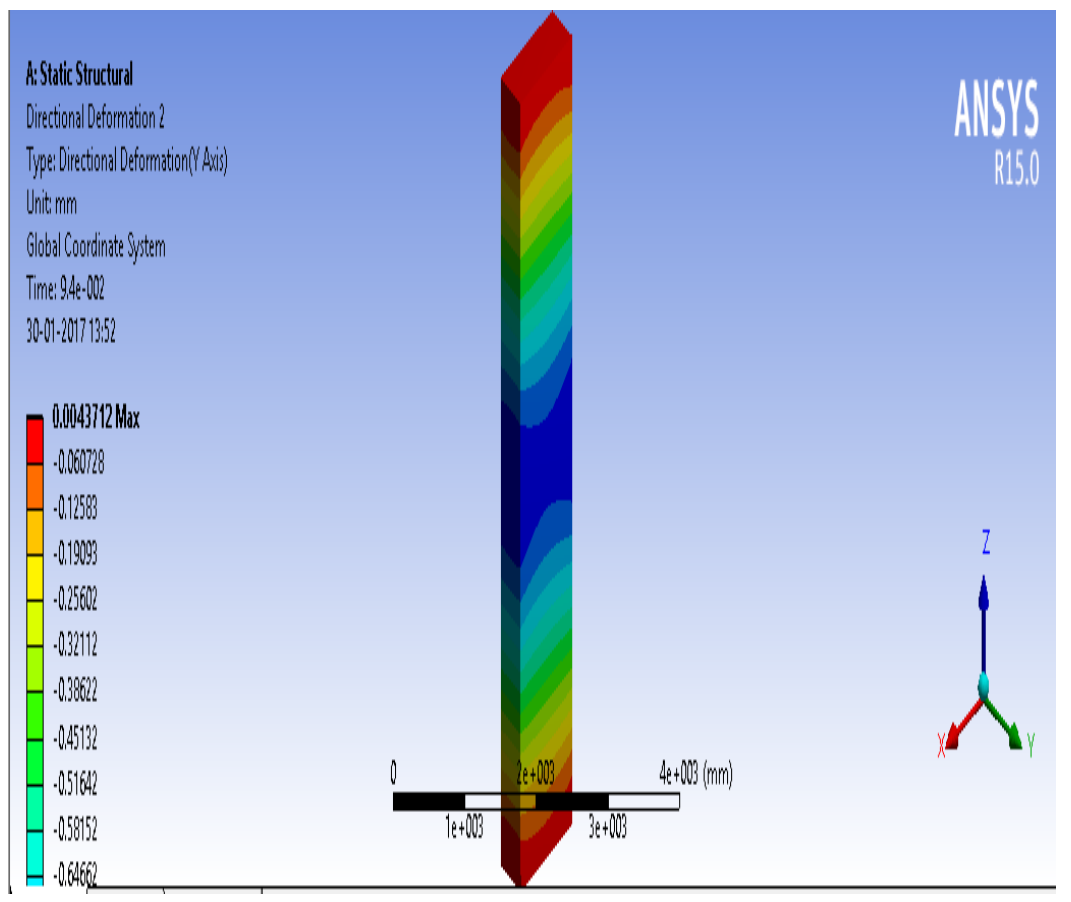

Figure 3: Displacement in the X-direction 


\begin{tabular}{|c|c|c|c|}
\hline & Time [s] & $\sqrt{\sim}$ Minimum $[\mathrm{mm}]$ & I Maximum [mm] \\
\hline 1 & 2.e-005 & -2.3484 & $4.7859 e-003$ \\
\hline 2 & 4.e-005 & -2.3492 & $4.7986 e-003$ \\
\hline 3 & 7.e-005 & -2.3487 & $4.8 e-003$ \\
\hline 4 & 1.e-004 & -2.3489 & $4.8001 e-003$ \\
\hline 5 & $4.8 e-004$ & -2.3428 & $4.7983 e-003$ \\
\hline 6 & $8.6 e-004$ & -2.3367 & $4.7963 e-003$ \\
\hline 7 & $1.43 e-003$ & -2.3275 & $4.7935 e-003$ \\
\hline 8 & $2 . e-003$ & -2.3183 & $4.7907 e-003$ \\
\hline 9 & $2.4 e-003$ & -2.3122 & $4.7889 e-003$ \\
\hline 10 & $2.8 \mathrm{e}-003$ & -2.3061 & $4.787 e-003$ \\
\hline 11 & $3.4 e-003$ & -2.2969 & $4.7842 e-003$ \\
\hline 12 & $4 . e-003$ & -2.2877 & $4.7814 e-003$ \\
\hline 13 & $4.4 e-003$ & -2.2816 & $4.7796 \mathrm{e}-003$ \\
\hline 14 & $4.8 e-003$ & -2.2755 & $4.7776 \mathrm{e}-003$ \\
\hline 15 & $5.4 e-003$ & -2.2663 & $4.7748 \mathrm{e}-003$ \\
\hline 16 & $6 . e-003$ & -2.2571 & $4.772 \mathrm{e}-003$ \\
\hline 17 & $6.4 e-003$ & -2.251 & $4.7702 \mathrm{e}-003$ \\
\hline 18 & $6.8 e-003$ & -2.2448 & $4.7683 e-003$ \\
\hline
\end{tabular}

Figure 4: Maximum and minimum displacement in X-direction

From the fig. 3 it was seen that the maximum displacement is on the top most and the bottom most of the wall in the $\mathrm{x}$-direction. It signifies that end portion of the wall gets affected more if the displacement is considered in the X-direction.

Fig. 4 shows the maximum and minimum displacement of the RC front wall under blast loading and the deformation that is getting is very low. So it is safe in design.

Similarly the deformation in the Y-direction is considered and regarding to that analysis is done in ANSYS software.

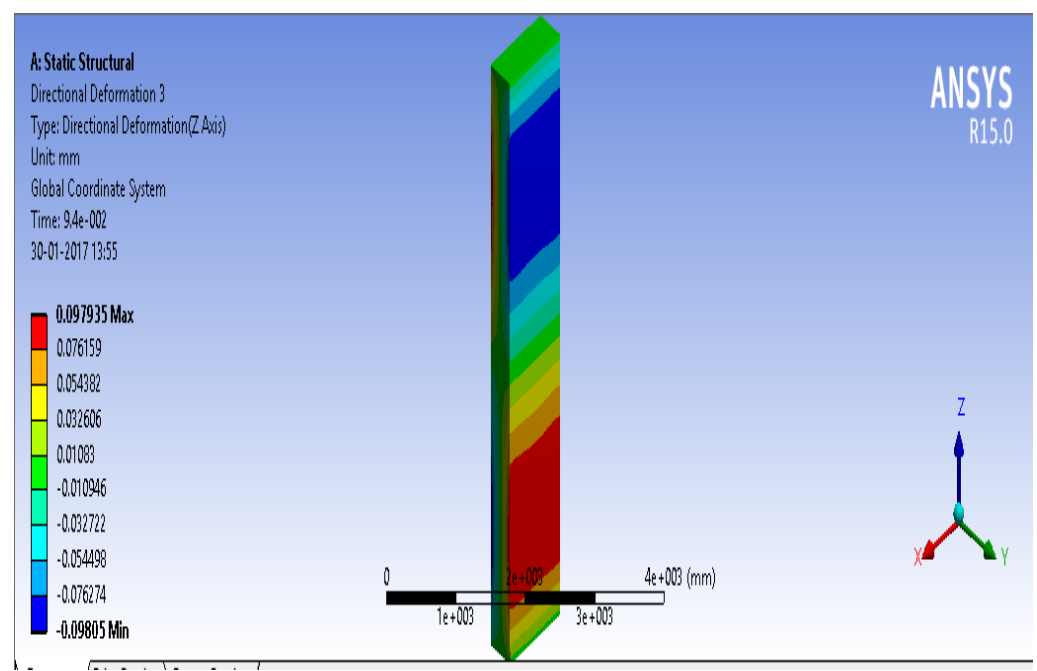

Figure 5: Displacement in the Y-direction 
From fig.5 lit was clearly seen that the maximum deformation is occurring in the lowest most region of the RC front wall considering the deformation in the Y-direction.

\begin{tabular}{|l|l|l|l}
\hline & Time $[\mathrm{s}]$ & $\sqrt{ }$ Minimum $[\mathrm{mm}]$ & $\sqrt{ }$ Maximum $[\mathrm{mm}]$ \\
\hline 1 & $2 \cdot e-005$ & $-5.7007 \mathrm{e}-002$ & $5.683 \mathrm{e}-002$ \\
\hline 2 & $4 . e-005$ & $-5.703 \mathrm{e}-002$ & $5.6854 \mathrm{e}-002$ \\
\hline 3 & $7 . e-005$ & $-5.7015 \mathrm{e}-002$ & $5.6842 \mathrm{e}-002$ \\
\hline 4 & $1 . e-004$ & $-5.7023 \mathrm{e}-002$ & $5.6849 \mathrm{e}-002$ \\
\hline 5 & $4.8 \mathrm{e}-004$ & $-5.6912 \mathrm{e}-002$ & $5.6738 \mathrm{e}-002$ \\
\hline 6 & $8.6 \mathrm{e}-004$ & $-5.6798 \mathrm{e}-002$ & $5.6625 \mathrm{e}-002$ \\
\hline 7 & $1.43 \mathrm{e}-003$ & $-5.6629 \mathrm{e}-002$ & $5.6455 \mathrm{e}-002$ \\
\hline 8 & $2 . e-003$ & $-5.6459 \mathrm{e}-002$ & $5.6285 \mathrm{e}-002$ \\
\hline 9 & $2.4 \mathrm{e}-003$ & $-5.6346 \mathrm{e}-002$ & $5.6172 \mathrm{e}-002$ \\
\hline 10 & $2.8 \mathrm{e}-003$ & $-5.6233 \mathrm{e}-002$ & $5.6059 \mathrm{e}-002$ \\
\hline 11 & $3.4 \mathrm{e}-003$ & $-5.6063 \mathrm{e}-002$ & $5.589 \mathrm{e}-002$ \\
\hline 12 & $4 . e-003$ & $-5.5893 \mathrm{e}-002$ & $5.572 \mathrm{e}-002$ \\
\hline 13 & $4.4 \mathrm{e}-003$ & $-5.578 \mathrm{e}-002$ & $5.5608 \mathrm{e}-002$ \\
\hline 14 & $4.8 \mathrm{e}-003$ & $-5.5667 \mathrm{e}-002$ & $5.5494 \mathrm{e}-002$ \\
\hline 15 & $5.4 \mathrm{e}-003$ & $-5.5497 \mathrm{e}-002$ & $5.5325 \mathrm{e}-002$ \\
\hline 16 & $6 . e-003$ & $-5.5327 \mathrm{e}-002$ & $5.5155 \mathrm{e}-002$ \\
\hline 17 & $6.4 \mathrm{e}-003$ & $-5.5214 \mathrm{e}-002$ & $5.5042 \mathrm{e}-002$ \\
\hline 18 & $6.8 \mathrm{e}-003$ & $-5.5101 \mathrm{e}-002$ & $5.4929 \mathrm{e}-002$ \\
\hline \multicolumn{5}{r}{ Graphics } & Tabular Data & \\
\hline
\end{tabular}

Figure 6: Maximum and minimum displacement in Y-direction

In this direction the deformation is more as compare to the X-direction when the wall is subjected to the blast loading.

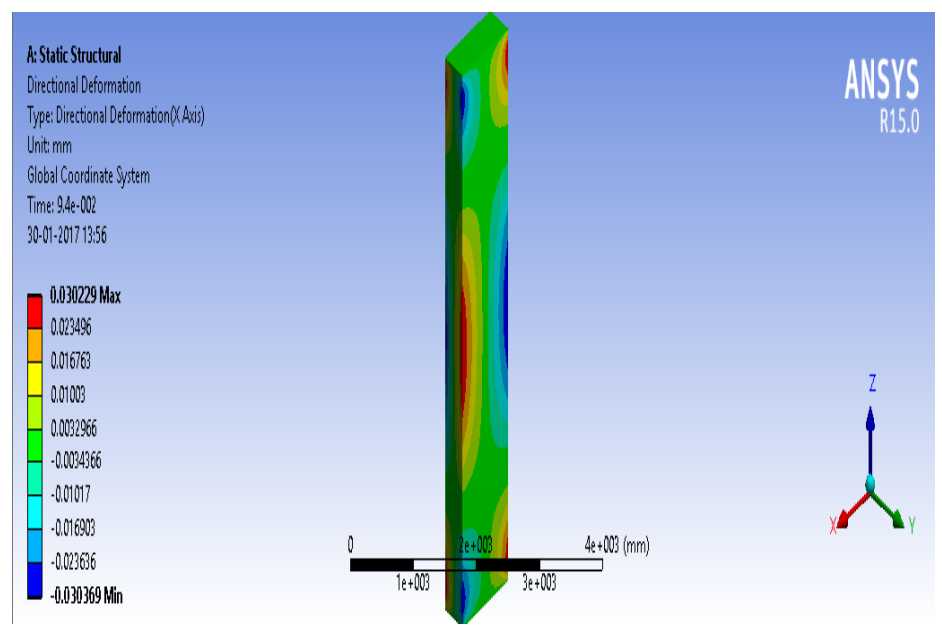

Figure 7: Displacement in the Z-direction 


\begin{tabular}{|c|c|c|c|}
\hline & Time [s] & $\sqrt{V}$ Minimum [mm] & $\sqrt{ }$ Maximum $[\mathrm{mm}]$ \\
\hline 1 & $2 . e-005$ & $-5 . \overline{7007 e-002}$ & $5.683 e-002$ \\
\hline 2 & 4.e-005 & $-5.703 e-002$ & $5.6854 \mathrm{e}-002$ \\
\hline 3 & 7.e-005 & $-5.7015 e-002$ & $5.6842 e-002$ \\
\hline 4 & $1 . e-004$ & $-5.7023 e-002$ & $5.6849 e-002$ \\
\hline 5 & $4.8 e-004$ & $-5.6912 e-002$ & $5.6738 e-002$ \\
\hline 6 & $8.6 e-004$ & $-5.6798 e-002$ & $5.6625 e-002$ \\
\hline 7 & $1.43 e-003$ & $-5.6629 e-002$ & $5.6455 e-002$ \\
\hline 8 & 2.e-003 & $-5.6459 e-002$ & $5.6285 e-002$ \\
\hline 9 & $2.4 e-003$ & $-5.6346 e-002$ & $5.6172 e-002$ \\
\hline 10 & $2.8 e-003$ & $-5.6233 e-002$ & $5.6059 e-002$ \\
\hline 11 & $3.4 e-003$ & $-5.6063 e-002$ & $5.589 e-002$ \\
\hline 12 & 4.e-003 & $-5.5893 e-002$ & $5.572 e-002$ \\
\hline 13 & $4.4 e-003$ & $-5.578 e-002$ & $5.5608 e-002$ \\
\hline 14 & $4.8 e-003$ & $-5.5667 e-002$ & $5.5494 e-002$ \\
\hline 15 & $5.4 e-003$ & $-5.5497 e-002$ & $5.5325 e-002$ \\
\hline 16 & $6 . e-003$ & $-5.5327 e-002$ & $5.5155 e-002$ \\
\hline 17 & $6.4 e-003$ & $-5.5214 e-002$ & $5.5042 e-002$ \\
\hline 18 & $6.8 \mathrm{e}-003$ & $-5.5101 e-002$ & $5.4929 e-002$ \\
\hline
\end{tabular}

Figure 8: Maximum and minimum displacement in Z-direction

In this the deformation is more on the edges and the deformation that is getting is same as the deformation in the Y-direction.

\section{RESULT AND CONCLUSION}

From the above analysis of RC wall under blast loading following points are observed:

1. In this paper it is observed that for SDOF system the Biggs Shape function is well defined in IS Code but not for MDOF.

2. Also the Nonlinear analysis of RC wall shows less deformation than standard mentioned in IS Code.

3. Biggs shape function was well defined in the IS: 4991-1968 and in this paper it was shown by manually calculation also.

4. The deflection in X-direction is comparatively less as compare to $\mathrm{Y}$ - direction and Zdirection.

5. Maximum deflection in $\mathrm{X}, \mathrm{Y}$ and $\mathrm{Z}$ direction are $0.0047 \mathrm{~mm}, 0.0568 \mathrm{~mm}$ and $0.0568 \mathrm{~mm}$ respectively.

6. The same analysis can be done for different boundary condition. 


\section{References}

1. A. Khadid et al., "Blast loaded stiffened plates"Journal of Engineering and Applied Sciences,Vol.2(2), 2007 pp. 456-461.

2. Biggs, J.M. (1964), "Introduction to Structural Dynamics", McGraw-Hill, New York.

3. IITK-GSDMA guidelines on measures to mitigate effects of terrorist attacks on buildings May 2006.

4. M. V. Dharaneepathy et al.,"Critical distance for blast resistance design”, computer and structure Vol. 54, No.4.pp.587-595, 1995.

5. Newmark N.M.,"An engineering approach to blast resistant design", American society of civil engineer, 1953.

6. Nicholas Rouzsky, "Blast resistant control building” Else science publisher, 1988. 